\title{
Echographic findings in the late stages of Vogt-Koyanagi-Harada disease in mexican population
}

\author{
Resultados ecográficos nas fases atrasadas da doença \\ de Vogt-Koyanagi-Harada na população mexicana
}

Mariana Mayorquín-Ruiz², Rashel Cheja-Kalb², Luz Elena Concha-del Río², Lourdes Arellanes-García², Eduardo Moragrega-Adame ${ }^{1}$

\begin{abstract}
Purpose: To correlate clinical findings of Vogt-Koyanagi-Harada disease with standardized echography findings in a cross-sectional, descriptive and observational study. Methods: Patients with Vogt-Koyanagi-Harada disease in the convalescent and recurrence phases were evaluated with standardized ocular echography. Eyes with opaque media were excluded. Clinical findings were correlated with echographic data. Results: Thirty-seven eyes of 25 patients were included. Best corrected visual acuity was in average 20/100 (0.70 logMAR). Clinical findings included: sunset glow fundus ( $92 \%)$, pigment migration (92\%), nummular chorioretinal depigmented scars $(68 \%)$ and subretinal fibrosis $(64.8 \%)$. Standardized echography was able to recognize all the cases with subretinal fibrosis $(n=24)$ described clinically. Standardized echography showed a 100\% sensitivity and specificity of finding subretinal fibrosis. Subretinal fibrosis in patients with Vogt-Koyanagi-Harada represents a risk factor for low vision. In our patients' eyes, presence of subretinal fibrosis had a 2.5 time relative risk of having a visual acuity equal or worst to 20/70. Conclusion: Standardized echography represents a useful tool in patients with VKH in the chronic (convalescence and recurrence) phase of the disease. Subretinal fibrosis, a sight threatening complication in the convalescence and recurrent phases of Vogt-Koyanagi-Harada, can be diagnosed with ocular echography, with characteristic images. Knowledge of these images can be useful in cases with opaque media and bilateral anterior segment granulomatous inflammatory disease.
\end{abstract}

Keywords: Uveomeningoencephalitic syndrome/diagnosis; Ultrasonography; Retinal diseases/diagnosis; Fibrosis/diagnosis

\section{RESUMO}

Objetivo: Correlacionar achados clínicos da síndrome de Vogt-Koyanagi-Harada com resultados ecográficos padronizado da doença em um estudo transversal, descritivo e observacional. Métodos: Pacientes com a doença de Vogt-Koyanagi-Harada, o convalescente e recorrência em fases padronizadas foram avaliados com ecografia ocular. Olhos com material opaco foram excluídos. Achados clínicos foram correlacionados com dados ecográficos. Resultados: Um total de 25 pacientes e trinta e sete olhos foram incluídos no estudo. A acuidade visual (AV) 20/100 foi em média $0.70 \log$ MAR. Os achados clínicos incluídos: sunset glow fundus (92\%), pigmento migração (92\%), numular despigmentado cicatrizes coriorretinianas (68\%) e fibrose sub-retiniana $(64,8 \%)$. A ecografia padronizada foi capaz de reconhecer todos os casos de fibrose sub-retiniana $(n=24)$ descrito clinicamente. A ecografia revelou um padrão $100 \%$ de sensibilidade e especificidade do diagnóstico fibrose sub-retiniana. Sub-retiniana em pacientes com fibrose Vogt-Koyanagi-Harada representa um fator de risco para a baixa visão. Em nossos pacientes olhos, presença de fibrose subretiniana tinham um risco relativo 2,5 hora de ter uma acuidade visual igual ou pior para 20/70. Conclusão: Ecografia padronizadarepresenta uma ferramenta útil em pacientes portadores da doença na fase crônica (convalescença, e recidiva). Fibrose sub-retiniana, uma visão ameaçadora e complicação na convalescença e recorrentes nas fases da Síndrome de Vogt-KoyanagiHarada, podem ser diagnosticados com ecografia ocular, com imagens características. O conhecimento dessas imagens pode ser útil em casos com material opaco e segmento anterior bilateral da doença inflamatória granulomatosa.

Descritores: Síndrome uveomeningoencefálica/diagnóstico; Ultrassonografia; Doenças retinianas; Fibrose/diagnóstico

${ }^{1}$ Servicio de ecografía, Asociación para evitar la ceguera en México - México;
${ }^{2}$ Servicio de enfermedades inflamatorias oculares, Asociación para evitar la ceguera en México - México.

The authors declare no conflicts of interest

Recebido para publicação em 14/2/2014 - Aceito para publicação em 16/9/2014

Rev Bras Oftalmol. 2014; 73 (6): 348-50 


\section{INTRODUCTION}

$\mathbf{V}$ ogt- Koyanagi-Harada (VKH) disease is a multisystemic inflammatory condition targeting melanocytes through the body. Its prevalence is higher in pigmented populations and it is known that certain populations have a genetic predisposition to develop it. In the Inflammatory Eye Disease Clinic in our hospital, VKH represents $2.4 \%$ of 6422 patients in a 20 -year period ${ }^{(1)}$.

VKH is clinically divided early and late manifestations ${ }^{(2)}$, each one with characteristic signs and symptoms. The late manifestations of the disease include: ocular depigmentation (sunset glow fundus and Sugiura sign) and nummular chorioretinal depigmented scars, retinal pigment clumping and/ or migration and recurrent or chronic anterior uveitis.

Diagnosis of VKH is merely clinical. The diagnostic criteria includes in cases of equivocal fundus findings in the early stages: fluorescein angiography and ultrasonography. Cerebrospinal fluid analysis is also useful when differential diagnosis have to be ruled out.

Ultrasound findings have been made in cases of early VKH: diffuse thickening of the choroid, serous retinal detachment, vitreous condensations ${ }^{(3)}$ and serous choroidal detachment ${ }^{(4)}$. High frequency ultrasound has shown characteristic images in the early VKH: shallow anterior chamber, ciliochoroidal detachment, thickened ciliary body, and narrow angles. Ultrabiomicroscopy has also been useful in monitoring treatment in the acute phases of the disease ${ }^{(5)}$.

Description of the echographic changes in the convalescent and recurrence phase have not been made.

\section{MethodS}

The study was reviewed and approved by the Hospital Ethics Committee. All the patients gave their informed consent prior to their inclusion in the study.

We included patients of the Inflammatory Eye Diseases Clinic at the Asociación para Evitar la Ceguera en México, with diagnosis of VKH in late stages, according to the International Committee on Nomenclature of $\mathrm{VKH}^{(2)}$. Eyes with opaque media, such as: cataract, posterior sinequiae, opaque posterior lens capsule, which precluded ophthalmoscopic evaluation of posterior pole, were excluded. Demographic data of patients were obtained. Best corrected visual aquity (BCVA), presence of anterior uveitis and changes characteristic of late VKH were noted: sunset glow fundus, Sugiura sign, nummular chorioretinal depigmented scars, retinal pigment epithelium clumpling and/or migration and subretinal fibrosis. After clinical evaluation, standardized ocular ultrasound was made (CineScan-S, Quantel Medical, Paris, France). Previous application of topical anesthetic, with the patient in supine decubitus, a $10 \mathrm{MHz}$ and $20 \mathrm{MHz}$ Bscan probes were used to analyze anteroposterior, longitudinal and transversal projections in 3, 6,9 and 12 meridian. Axial length of the eye was measured. Any abnormal image of the chorioretinal structures were then measured and analyzed with an $8 \mathrm{MHz}$ standardized A probe. Choroid thickness was measured with $8 \mathrm{MHz} \mathrm{A}$-scan probe at the equator of meridian 12. Clinical evaluations were made by two ophthalmologists (RCK and LECR), ocular ultrasound were done by the same ophtalmologist (MMR).
Table 1

\section{Clinical findings in 37 eyes of 25 patients with VKH disease in the late stages}

\begin{tabular}{lr}
\hline & n (\%) \\
\hline Sunset fundus glow & $35(92)$ \\
Nummular chorioretinal depigmented scars & $26(68)$ \\
Retinal pigment epithelium migration & $35(92)$ \\
Subretinal fibrosis & $24(64.8)$ \\
Anterior segment inflammation & $5(31)$ \\
Posterior segment inflammation & 0 \\
\hline
\end{tabular}

Table 2

\section{Echographic findings in 37 eyes in the late stages of VKH disease}

\begin{tabular}{lr}
\hline Variable & n (\%) \\
\hline Type of eye & phakic 19 $(51.3)$ \\
& pseudophakic 15 (40.5) \\
Mean axial length & aphakic 3 (8.1) \\
$\begin{array}{l}\text { Vitreous } \\
\text { Retina }\end{array}$ & 22.93 mm (SD 1.04 mm) \\
Choroid thickness at & Posterior vitreous detachment 16 (43.2) \\
XII meridian, equator & Attached 37 (100) \\
\hline
\end{tabular}

\section{RESULTS}

Thirty seven eyes of 25 patients with VKH in the chronic phase of the disease were included. Twenty female and 5 male with a mean age of 43 years (6-60 years). All patients were from a mexican mestizo population.

Best corrected visual acuity was in average 20/100 (0.70 $\log$ MAR). Clinical findings are listed in table 1 . Table 2 shows the echographic findings.

Recurrence of the disease was seen in five eyes (31\%) with anterior segment inflammation.

Standardized echography was able to recognize all the cases with subretinal fibrosis $(\mathrm{n}=24)$ described clinically. Standardized echography was not able to find any of the rest of clinical findings. Characteristics of subretinal fibrosis in standardized echography were:

Dome shaped, heterogeneous lesion (Figure 1), variable height. Mean height $1.47 \mathrm{~mm}(1.83 \mathrm{~mm}-4.2 \mathrm{~mm})$, major base dimension $4.61 \mathrm{~mm}(1 \mathrm{~mm}$ to $12.4 \mathrm{~mm})$, uni or bilobulated, located in a single area $(58.3 \%)$ o less common in multiple areas $(41.6 \%)$.

Most of them were peripapilar $(66.6 \%)$ or located in the posterior pole $(33.3 \%)$, not exceeding equator. Subretinal fibrosis showed mild to moderate posterior attenuation (Figure 2), and internal reflectivity was medium-high.

Standardized echography showed a $100 \%$ specificity and $100 \%$ sensitivity of describing an image compatible with subretinal fibrosis; when the localization was peripapilar or in the macular area. In the cases of subretinal fibrosis elsewhere, specificity was $96 \%$.

Eyes with subretinal fibrosis had a relative risk of 2.5 of having a BCVA less than 20/70 (confidence interval 0.87-7.1\%). 

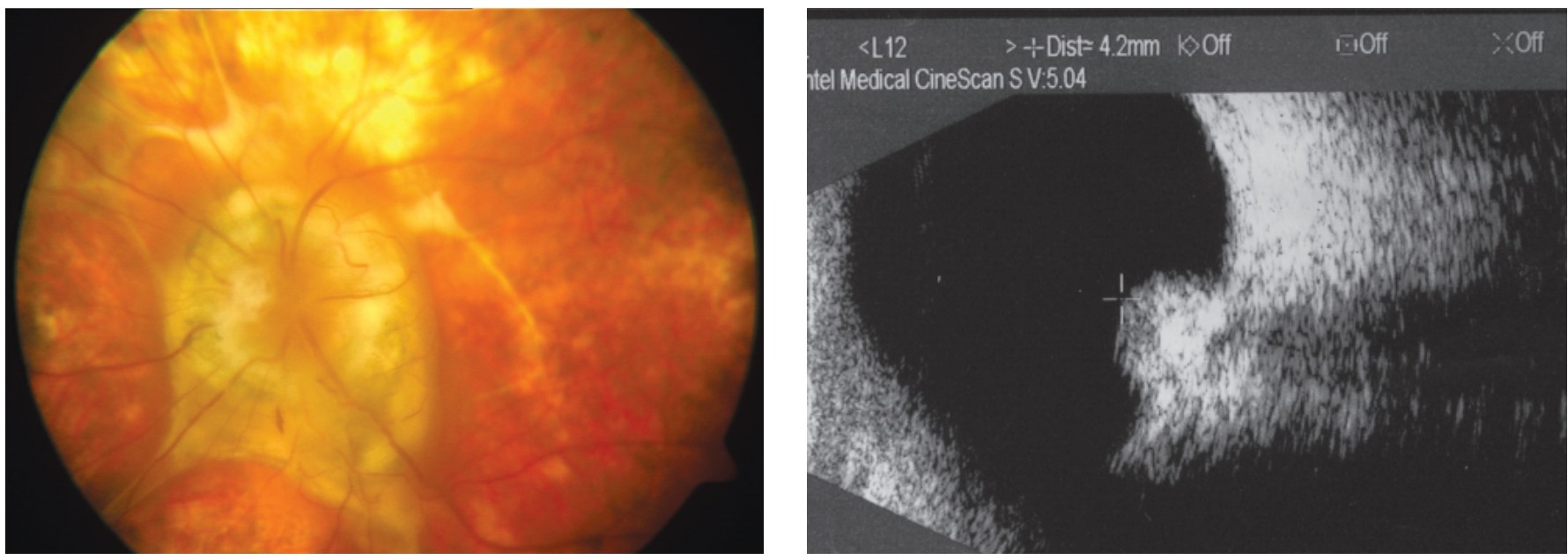

Figure 1: Fundus photograph in a patient with peripapilary subretinal fibrosis and echographic appearance

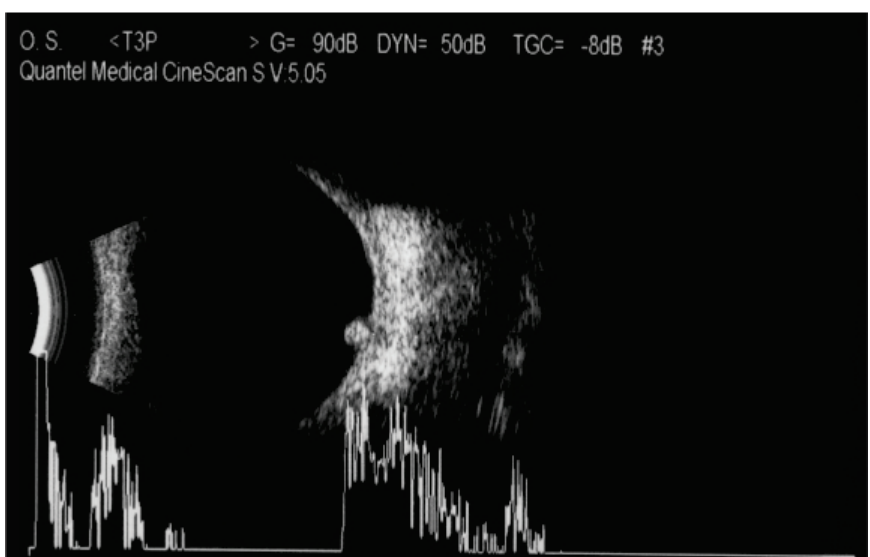

Figure 2: Echographic findings in 37 eyes in the late stages of $\mathrm{VKH}$ disease

\section{Discussion}

Ocular ultrasound have demonstrated its usefullness in VKH disease: from distinguishing differential diagnosis like posterior scleritis, in which the subtenon space is seen as hypoecoic and, together with the optic nerve shadow gives the characteristic " $\mathrm{T}$ " sign; to the resolution of the characteristic changes with therapy.

From all the clinical changes that occurred in the late stages of VKH, subretinal fibrosis was the only one perceptible for ocular echography in our patients. It occurred in $64.8 \%$ of the eyes studied. The impact of subretinal fibrosis on the disease, refers to the poor visual acuity founded in these eyes compared to the ones that do not develop subretinal fibrosis ${ }^{(6)}$. It is considered a complication of $\mathrm{VKH}$, that depends of the duration of the disease, and it has been noticed in other reports ${ }^{(7)}$, that hispanic patients develop subretinal fibrosis quicker than non-hispanic patients.

In the 5 eyes with anterior segment inflammation, we did not find increase in the choroidal thickness compared to the patients that did not have anterior segment inflammation.

Of the dome shaped lesions that we must keep in mind when doing a standardized echography is the choroidal melanoma, that can be distinguished from subretinal fibrosis by its internal reflectivity, which is medium-low and presence of vascularity signs. In contrast with the heterogenicity of subretinal fibrosis and medium-high reflectivity and abscence of vascularity signs on echography.

\section{Conclusion}

Standardized echography should be considered a useful tool in patients with $\mathrm{VKH}$ in the late stages of the disease (recurrence and convalescence). Subretinal fibrosis, a sight threatening complication, can be diagnosed with ocular echography, with characteristic images. Knowledge of these images can be useful in future cases with opaque media and anterior segment granulomatous inflammatory disease.

\section{References}

1. Concha del Rio LE, Arellanes García L. Vogt Koyanagi-Harada in the developing world. Int Ophthalmol Clin. 2010;50(2):189-99.

2. Read RW, Holland GN, Rao NA, Tabbara KF, Ohno S, ArellanesGarcia L, et al. Revised diagnostic criteria for Vogt-KoyanagiHarada Disease: report of an International Committee on Nomenclature. Am J Opthalmol. 2001;131(5):647-52.

3. Forster DJ, Cano MR, Green RL, Rao NA. Echographic features of Vogt-Koyanagi-Harada syndrome. Arch Ophthalmol. 1990;108(10):1421-6.

4. Yamamoto N, Naito K. Annular choroidal detachment in a patient with Vogt-Koyanagi-Harada disease. Graefes Arch Clin Exp Ophthalmol. 2004;242(4):355-8.

5. Wada S, Khono T, Yanagihara N, Hirabayashi M, Tabuchi H, Shiraki $\mathrm{K}$, et al. Ultrasound biomicroscopy study of ciliary body changes in the post treatment phase of Vogt Koyanagi Harada disease. Br J Ophthalmol. 2002;86(12):1374-9.

6. Lertsumitkul S, Whitcup SM, Nussenblatt RB, Chan CC. Subretinal fibrosis and choroidal neovascularization in VogtKoyanagi-Harada syndrome. Graefes Arch Clin Exp Ophthalmol. 1999;237(12):1039-45.

7. Kuo IC, Rechdouni A, Narsing AR, Johnston RH, Margolis TP, Cunningham ET. Subretinal fibrosis in patients with Vogt-KoyanagiHarada Disease. Ophthalmology. 2000;107(9):1721-8.

\section{Corresponding author:}

Mariana Mayorquín-Ruiz

Address: Asociación para evitar la Ceguera en México

Vicente García Torres 46. Col. San Lucas, Coyoacán

Mexico City - 04360

phone number: (55) 10841400

E-mail.marianamayorquinruiz@me.com 